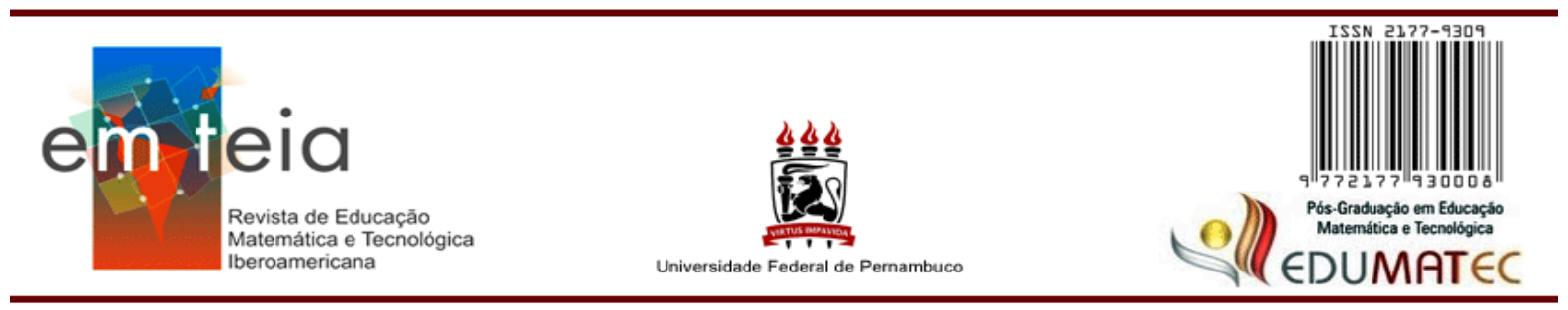

\title{
A IMPLEMENTAÇÃO DO MOVIMENTO DA MATEMÁTICA MODERNA NOS ANOS INICIAIS NO ESTADO DE SÃO PAULO
}

\author{
Denise Medina de Almeida França \\ Universidade do Estado do Rio de Janeiro (UERJ) \\ denisemedinafranca@gmail.com \\ Aparecida Rodrigues Silva Duarte \\ Universidade do Vale do Sapucaí (UNIVÁS/MG) \\ aparecida.duarte6@gmail.com
}

\section{Resumo}

Este artigo discute as ideias defendidas pelo Movimento da Matemática Moderna (MMM), nas décadas de 1960 e 1970, para os anos iniciais, no estado de São Paulo, Brasil. A periodicidade do texto relaciona-se a um período de expansão e criação dos sistemas de ensino no Brasil, com transformações na estrutura, no funcionamento, nos programas e no currículo de Matemática, de acordo com as normativas impostas pelas Leis de Diretrizes e Bases 4.024/61 e 5.692/71. Na articulação das questões, fez-se uso da abordagem da História Cultural, apoiada nos conceitos de representação, apropriação e estratégias, colocadas por Chartier (1991) e De Certeau (1982). Verificou-se que as propostas do MMM foram consideradas as mais adequadas, em grande medida devido à necessidade de democratização do ensino, pela possibilidade de ser utilizada como estratégia para implementar a reformulação curricular e de divulgar novas diretivas para o ensino de Matemática nas séries iniciais, oferecendo instrumentos para o acesso a uma nova sociedade tecnológica e mais científica.

Palavras-chave: História da educação matemática. Movimento da Matemática Moderna. Educação matemática nas séries iniciais. Didática da matemática. Documentos oficiais.

\begin{abstract}
This article discusses the ideas defended by the Modern Mathematics Movement (MMM) in the 1960s and 1970s, for the initial years, in the state of São Paulo, Brazil. The periodicity of the text is related to a period of expansion and creation of education systems in Brazil, with changes in the structure, operation, programs and mathematics curriculum, in accordance with the regulations imposed by the Laws of Guidelines and Bases 4.024 / 61 and 5.692 / 71. In the articulation of the questions, the Cultural History approach was used and supported by the concepts of representation, appropriation and strategies, put by Chartier (1991) and De Certeau (1982). It was verified that the proposals of the MMM were considered the most adequate, largely due to the need for democratization of education, for the possibility of being used as a strategy to implement the curricular reformulation and to disseminate new directives
\end{abstract}


for the teaching of Mathematics, offering instruments for access to a new, more scientific and technological society.

Key words: History of mathematical education. Modern Mathematics Movement. Mathematics education. Didactics of mathematics primary education. Official documents.

\section{Introdução}

Na década de 1960, surgia a construção de uma estrutura organizacional, por parte do poder público brasileiro, responsável por gerir as ações para expandir o número de vagas no estado de São Paulo. Os processos de modificação, organização e expansão da escola primária, principalmente em São Paulo, foram fatores relevantes para indicar as condições que permitiram a dinâmica de implantação das propostas de alterações metodológicas, que levaram em conta o ideário do Movimento da Matemática Moderna (MMM).

Os defensores desse Movimento acreditavam que a compreensão da Matemática Moderna pelos cidadãos facilitaria a apropriação de novas tecnologias e contemplaria as demandas da "nova sociedade". Para isso, uma nova metodologia para seu ensino deveria ser adotada, de forma a desenvolver a capacidade de pensar do estudante, propiciando-lhe instrumentos matemáticos úteis no novo cotidiano e de acesso mais fácil aos conteúdos.

Pretendiam unificar a Matemática em função de três grandes "estruturas-mãe"1, propostas por um grupo internacional de matemáticos, denominado por Bourbaki. Segundo Vitti (1998, p. 55), esse grupo Nicolas Bourbaki é o pseudônimo sob o qual um grupo de matemáticos, na maioria francesa, escreve uma série de livros que expõem a Matemática Moderna, que começam a ser editados em 1935. O grupo difundia, em livros e artigos, mudanças no ensino da Matemática, numa concepção estruturalista e abstrata, pregando a utilização de uma abordagem lógico-dedutiva, e defendia uma revolução interna na Matemática com base no desenvolvimento e estudo da noção de estrutura.

\footnotetext{
1 As estruturas matemáticas fundamentais são: 1) Algébricas: dado um conjunto inicial de objetos, uma operação (algébrica) é um conjunto de pares em que o primeiro termo é, ele mesmo, um par de objetos (os termos da operação) e o segundo é outro objeto (o resultado da operação). Somar e multiplicar são operações nesse sentido. Numa estrutura algébrica, respondemos a perguntas do seguinte tipo: dado um par de objetos (a, b) obtemos um terceiro objeto c; 2) Ordem: dado um conjunto inicial de objetos, uma ordem é um conjunto de pares sujeitos a certas restrições: assim, por exemplo, se o par $(a, b)$ pertence à ordem, então $(b, a)$ não pertence à ordem (a não ser que a e b sejam o mesmo objeto). Numa estrutura de ordem, respondemos assim a perguntas sobre pares de objetos: para cada dois objetos distintos como a e b, uma estrutura de ordem deve responder se vale (a, b) ou se vale (b, a), ou se a e b são incomparáveis; 3) Estruturas topológicas: são modelos da noção de proximidade, no mesmo sentido em que estruturas de ordem modelam escolhas e estruturas algébricas modelam operações. Então, dados dois objetos (a, b), em uma topologia (que tenha uma métrica), sabemos qual é a distância entre eles. Com a topologia ganham sentido noções de inclusão, proximidade, fronteira, limite, continuidade e descontinuidade (ALMEIDA, 1999).
} 
Além da linguagem da Teoria dos Conjuntos, usada para a unificação dos conteúdos, os matemáticos defendiam uma abordagem axiomática e dedutiva para a disciplina. Naquela época, Jean Piaget afirmava que havia uma forte relação entre o desenvolvimento das estruturas psicológicas do indivíduo e a forma de ensinar Matemática sugerida pelos "modernistas". Assim, a teoria cognitiva piagetiana e as ideias do grupo Bourbaki serviram como sustentação teórica e de argumentação para convencimento das propostas do MMM. Tanto as ideias de Piaget como de Bourbaki foram muito usadas pelos "modernistas" para justificar, incentivar e validar o emprego de metodologias experimentais.

Desse cenário emerge a finalidade deste artigo, qual seja, discutir as condições que possibilitaram a implementação do MMM no estado de São Paulo nas séries iniciais, e sobre como ensinar Matemática nas propostas defendidas pelo MMM, divulgadas como as mais pertinentes e eficazes para serem utilizadas nas escolas públicas do estado de São Paulo.

\section{Apontamentos teórico-metodológicos}

Neste tópico discorremos sobre as normativas da Secretaria de Educação (SEE) e da Secretaria Municipal de Educação (ME) do estado de São Paulo, decorrentes das leis 4.024/1961 e 5.692/1971. Entendemos essas normativas como estratégias do Estado de São Paulo para expandir e democratizar seu sistema de ensino. Para tanto, adotamos o conceito de estratégia conforme definida por De Certeau (2002), para quem a estratégia.

[...] postula um lugar capaz de ser circunscrito como um próprio e portanto capaz de servir de base a uma gestão de suas relações com uma exterioridade distinta. A nacionalidade política, econômica ou científica foi construída segundo esse modelo estratégico [...] as estratégias escondem sob cálculos objetivos a sua relação com o poder que os sustenta, guardado pelo lugar próprio ou pela instituição (DE CERTEAU, 2002, p. 46-47).

No âmbito dos professores envolvidos com o MMM, alocados em lugar de poder em instituições incumbidas da elaboração e do oferecimento de cursos de formação, trazemos Chartier (1991) para auxiliar na compreensão da importância desse tipo de ação, que multiplica as trocas, as experiências e os encontros, permitindo ressignificar as representações ${ }^{2}$ postas e atribuindo maior inteligibilidade a cada realidade. $\mathrm{O}$ conceito de

\footnotetext{
2 Toda a tradução e interpretação mental de uma realidade exterior percebida. [...], as representações coletivas constroem o próprio mundo social: [...] construções que os grupos fazem sobre suas práticas e que não existem práticas que não sejam representadas. [...] A história cultural, tal como a entendeu, tem por principal objeto identificar o modo como em diferentes lugares e momentos uma determinada realidade social é construída, pensada, dada a ler. Uma tarefa deste tipo supõe vários caminhos. O primeiro diz respeito às classificações, divisões e delimitações que organizam a apreensão do mundo social como categorias fundamentais de percepção e de apreciação do real. Variáveis consoantes às classes sociais ou os meios intelectuais são produzidos pelas disposições estáveis e partilhados, próprios do grupo. São estes esquemas intelectuais
} 
apropriação, defendida por Chartier (1991), enfatiza esse consumo criativo efetuado pelos sujeitos em contato com os textos normativos e tem como objetivo a produção de "uma história social dos usos e das interpretações, referida às suas determinações fundamentais e inscritas nas práticas específicas que as produzem" (p. 178-180).

Nessa perspectiva, abrem-se possibilidades de fazer história com novos objetos, problemas e abordagens. No caso, a atenção volta-se sobre as diferentes representações atribuídas ao MMM. Dado que esse Movimento ocorreu num passado recente, pudemos realizar entrevistas com alguns elaboradores das publicações e com professores participantes de cursos de formação, a fim de entender a representação posta para o ensino de Matemática e suas repercussões. Optou-se por realizar entrevistas não estruturadas, gravadas em conversas informais de duração variável de modo que os entrevistados ficassem à vontade para discorrer e explorar amplamente o tema em questão.

A escolha das professoras entrevistadas para a coleta de dados, quais sejam, Manhucia P. Liberman, Lucília Bechara e Maria Amábile Mansutti, deveu-se ao prestígio que alcançaram junto aos professores das séries iniciais. Deslocaram seus interesses para a escola primária, de modo que produziram livros didáticos e ministraram cursos para professores sobre metodologia para esse nível de ensino. Além disso, ocuparam espaços dentro da Secretaria de Educação do estado de São Paulo, o que lhes possibilitou elaborar e fazer circular propostas contendo prescrições de como ensinar matemática moderna para os primeiros anos de escolaridade. Os depoimentos abordaram a participação, inserção e produção de propostas das entrevistadas no MMM nas séries iniciais.

Manhúcia Perelman Liberman, licenciada em matemática pela Faculdade Nacional de Filosofia do Rio de Janeiro, trabalhou no Serviço de Medidas e Pesquisas Educacionais, cuja tarefa consistia em formular e corrigir as provas de admissão ao ginásio, o que lhe permitia obter conhecimento sobre os conteúdos abordados na escola primária e se relacionar com os professores da rede estadual. Assumiu, em 1961, e coordenou a equipe responsável pela elaboração do Programa da Escola Primária de São Paulo (1968-1969)³. Foi uma das fundadoras do Grupo de Estudos do Ensino da Matemática (GEEM) e realizou diversos cursos de formação para professores. Autora de livros didáticos e artigos conhecidos e utilizados por grande parte dos professores das séries iniciais, veículos de utilização de novas

incorporados que criam as figuras graças às quais o presente pode adquirir sentido, o outro tornar-se inteligível e o espaço ser decifrado (CHARTIER, 1991, p. 16).

${ }^{3}$ Vale lembrar que, em períodos anteriores, programas, livros e outros materiais pedagógicos para o ensino primário, em geral, eram escritos por pedagogos ou professores primários, que se destacavam em seu ofício, e não por matemáticos (FRANÇA, 2012). 
práticas, fez circular propostas inovadoras para o ensino de Matemática. Publicou, juntamente com as professoras Lucília Bechara e Anna Franchi, a coleção de livros didáticos intitulada “Introdução da Matemática Moderna na Escola Primária” (FRANÇA, 2012).

Lucília Bechara, licenciada em matemática pela Faculdade de Filosofia Ciências e Letras da Universidade de Campinas, assumiu a supervisão geral dos Ginásios Vocacionais ${ }^{4}$ do Estado de São Paulo. Tal como Liberman, ministrou cursos de matemática moderna para professores primários no GEEM, sendo uma de suas fundadoras. Assumiu a coordenação do Colégio Peretz, ocasião em que teve possibilidade de experimentar novas metodologias e ter maior contato com professores primários, uma das razões para priorizar o ensino primário em suas produções (FRANÇA, 2012).

Formada em Pedagogia pela Universidade de São Paulo, Maria Amábile Mansutti foi uma das professoras protagonistas do MMM, também integrante do GEEM. Em 1969 fez parte da equipe que desenvolvia projetos experimentais para formação de escolas integradas de oito anos, do Instituto Municipal de Educação e Pesquisa (IMEP). Auxiliou na elaboração do Guia Curricular de Matemática do Núcleo Comum do ensino de primeiro grau do estado de São Paulo, em 1975. Foi coordenadora da equipe que elaborou Programas de Matemática para o Município de São Paulo, para a $1^{\text {a a }} 8^{\text {a }}$ série em 1981 (FRANÇA, 2012).

\section{As Leis 4.024/1961 e 5.692/1971 e as demandas por Educação no estado de São Paulo}

A Lei 4.024, de 20 de dezembro de 1961, foi considerada um avanço em prol da descentralização da educação. Hilsdorf (2005) acredita que a Lei 4.024 manteve as estruturas tradicionais do ensino, em relação às Leis Orgânicas ${ }^{5}$ de 1942-1946, exceto pela proposição de currículos flexíveis e de mecanismos democratizantes, do tipo aproveitamento de estudos entre o ensino técnico e o acadêmico.

Pela primeira vez, uma legislação conseguia fixar diretrizes gerais para a Educação nacional, ao abordar todos os níveis e com validade para todo território nacional, dando passos importantes para a unificação dos sistemas de ensino na descentralização e flexibilização curriculares. Também inovou ao propor um planejamento educacional e a abertura de novas experiências, como a criação dos ginásios vocacionais e pluricurriculares.

\footnotetext{
${ }^{4}$ Escolas de aplicação do estado de São Paulo, destinados a alunos com idade entre 11 e 13 anos, aprovados nos exames de admissão.

${ }^{5}$ Durante o Estado Novo (1937-1945), com a Reforma Capanema, sob o nome de Leis Orgânicas do Ensino, que estruturou o ensino industrial, reformou o ensino comercial e criou o Serviço Nacional de Aprendizagem Industrial (SENAI), como também trouxe mudanças no ensino secundário. Gustavo Capanema esteve à frente do Ministério da Educação durante o governo Getúlio Vargas, entre 1934 e 1945 (RIBEIRO, 1986, p. 120).
} 
Segundo Romanelli (1982), apesar da liberdade de ensino para os Estados constituírem seus currículos deliberados na lei, na prática nada mudou, pois os menos favorecidos mantinham a educação que lhes era possível, em virtude dos poucos recursos destinados à área. Na época, ainda não havia legislação específica sobre destinação e distribuição de recursos para a Educação.

Hilsdorf (2005) afirma que a discussão promovida em torno dos princípios de centralização e descentralização desviou da sociedade a atenção do problema que os educadores da época consideravam básico, que era como tornar acessível o ensino aos $50 \%$ de analfabetos existentes no país. Segundo ela, a lei foi aprovada nos termos propostos de apoio à iniciativa privada.

Essa legislação não cumpriu o compromisso constitucional de oferecer educação gratuita para todos. O governo criou, então, em 1962, o Conselho Federal de Educação, que aprovou o Plano Nacional de Educação para o período de 1962-1970. O Plano consistia, basicamente, em um conjunto de metas a serem alcançadas num prazo de oito anos. Almejava-se, por exemplo, matricular até a $4^{\mathrm{a}}$ série das séries iniciais, $100 \%$ da população escolar de 7 aos 11 anos de idade (Lei no 4.024, 1961). Segundo Romanelli (1982), o fracasso dessas metas ocorreu devido à impossibilidade da escola primária atender a toda população e aos seus altos índices de retenção.

Durante o governo militar, com uma política de desenvolvimentismo associado à economia, embasada na indústria e no capital estrangeiro, o Plano Nacional de Educação foi revisado e foram incluídas normas para estimular a elaboração dos planos estaduais. A aceleração no ritmo do crescimento econômico e na demanda social de educação agravou a crise do sistema educacional, justificando os vários acordos de colaboração técnica e financeira entre o Ministério da Educação e Cultura (MEC) e a United States Agency for International Development (USAID), os quais tinham o objetivo de diagnosticar e solucionar tais problemas, na perspectiva do desenvolvimento do capital humano.

No Brasil, são assinados doze acordos MEC-USAID, entre 1964 e 1968, que tomaram a forma de divulgação de metodologias de pesquisa, aumentando a introdução de técnicas de ensino modernizantes. Os acordos estavam vinculados a uma reorganização da escola fundamental. O governo precisava colocar todos na escola para formar mão de obra, com alguma educação e treinamento, e, ao mesmo tempo, que fosse muito produtiva e barata. Os conteúdos das áreas tecnológicas foram supervalorizados, manifestados na predominância de treinamentos nesses setores. 
Em novembro de 1968, foi criado o Fundo Nacional de Desenvolvimento da Educação (FNDE), cuja finalidade era angariar recursos e aplicá-los em financiamento de projetos de ensino. Percebe-se uma mudança na política de distribuição e aplicação de recursos da educação, agora subordinados às orientações do governo federal, em relação ao controle da política educacional, que se comportava como um regulador entre a produção educacional e as necessidades do desenvolvimento (Lei ${ }^{\circ} 5.537,1968$ ).

A década de 1970 foi marcada pelas mudanças ocorridas pela entrada de capital estrangeiro no Brasil. A rápida urbanização provocou aumento na procura de empregos e impeliu os empregadores a exigir um nível de escolaridade cada vez maior. Nesse período é instituída a Lei ${ }^{\circ}$ 5.692/1971.

A tendência tecnicista implantada pela Lei $n^{\circ} 5.692 / 1971$ surge com ênfase nas tecnologias do ensino, focando o processo de ensino-aprendizagem nos objetivos instrucionais e nas técnicas de ensino, com divisão do trabalho pedagógico entre os especialistas da educação. Havia preocupações com a economia de pensamento e o raciocínio rápido, demandados pela sociedade em desenvolvimento. Assim, a lei corroborava o ideário do MMM, em um período em que se encontrava bem consolidado no ensino primário.

O estado de São Paulo, com um grande crescimento demográfico e a urbanização provocada por mudanças socioeconômicas e políticas em favor do capitalismo industrial, pressionava o Governo a alargar o sistema educacional, impulsionando discussões sobre seu sistema de ensino. Em cumprimento ao Plano Nacional de Educação, o estado de São Paulo resolveu efetivar as medidas deliberadas pelo governo federal, por meio de seus órgãos competentes, já que possuía a maior população urbana e o maior déficit de vagas nas escolas primárias e necessitava das verbas federais para colocar em prática a expansão da rede no Estado. Assim, em 1967, o poder público estadual começou a articular a elaboração de um plano estadual de educação, advindo da necessidade de racionalização de esforços para o desenvolvimento de um sistema de ensino, defendida pelos técnicos dos acordos MECUSAID.

Nesse cenário, marcado pelo centralismo federal e redução da autonomia, a ação do governo estadual viu-se limitada. Na versão preliminar do Plano de Educação de São Paulo (SÃO PAULO, 1969), José Mario Pires Azanha, diretor geral do Departamento de Educação, anunciou as concepções do Estado sobre sistemas de ensino que corroboravam as do MECUSAID, ao dar ênfase ao planejamento e à organização racional das atividades pedagógicas. No entanto, os conflitos com as normativas postas pelo governo federal mostravam-se presentes. Azanha denunciava o problema de déficit de vagas no Estado, sugerindo a 
coordenação de recursos estaduais, municipais e particulares, associados às verbas federais, além da mobilização da opinião pública, a fim de que entidades particulares cedessem locais para a instalação de salas de aula. Na continuidade de seu discurso, Azanha reforçou o papel da escola primária como base para os outros níveis de ensino, devendo, por isso, reformularse pedagogicamente, diante das novas demandas da sociedade brasileira e do desenvolvimento das teorias de aprendizagem infantil.

Percebe-se a intenção de Azanha em limitar as funções conferidas à escola e, assim, viabilizar a entrada de um enorme contingente de crianças no ensino primário. Da mesma forma, era encarada a melhoria da qualidade, relacionada à reformulação de expectativas quanto à escola primária, justificada pela diminuição de seu poder na formação da criança. Nota-se, também, a intenção do Estado de dividir com outros segmentos da sociedade responsabilidades que antes eram suas. O diferencial proposto refere-se à flexibilidade do Plano, com insistência na possibilidade de existência de vários caminhos para o sucesso da reestruturação pretendida, não sendo conveniente que o ensino primário se organizasse segundo um único modelo, espaço para tentativas experimentais.

Os conceitos trabalhados por De Certeau são oportunos para nos ajudar a entender os mecanismos de implantação da reestruturação do sistema estadual de ensino. O Plano produzido pelo Estado (de um lugar de poder) foi utilizado como estratégia de imposição e divulgação de suas diretivas para o Ensino Primário. Esse discurso fez circular a nova política educacional, fundamentada nas ideias do capital humano, na concepção da necessidade de criar recursos humanos e tecnológicos, conforme o modelo de desenvolvimento econômico subordinado ao capital estrangeiro adotado no País.

\section{Os participantes do MMM na estrutura organizacional das Secretarias de Educação de São Paulo}

A organização dos cursos de formação, para a implantação das reformas de ensino do Estado, perpassou diferentes estratégias. O governo de São Paulo criou os Ginásios Vocacionais e Pluricurriculares, com classes experimentais, regulamentados pelo Decreto 38.643/1961, e um órgão denominado Serviço de Ensino Vocacional (SEV), destinado a coordenar os Ginásios Vocacionais (TAMBERLINI, 2001). 
Essas medidas geraram investimentos em formação de professores. Os cursos de formação ${ }^{6}$, nos primeiros anos da década de 60, oferecidos pela Secretaria de Educação, utilizados como estratégia de implementar mudanças, foram realizados de maneira assistemática, com critérios e objetivos pedagógicos não definidos claramente, em face de obscuridade de planejamento para operacionalização. Esses cursos foram organizados e oferecidos ao pessoal docente por várias instituições, órgãos ou serviços ligados ao governo (federal, estadual ou municipal), entidades privadas conveniadas pelo governo, escolas de caráter experimental etc. (GATTI; MELLO; BERNARDES, 1972).

Para Bechara (2007), os Ginásios Vocacionais continham propostas pedagógicas revolucionárias, com projeto e estrutura institucional diferenciada, que possibilitavam a implementação de uma série de inovações em relação à escola tradicional, com experiências que proporcionavam o desenvolvimento de novos métodos e processos de avaliação do aluno, currículo e vínculo da comunidade com a escola.

O Vocacional começou em 1961, eu fui supervisora da área de matemática de São Paulo e fazia supervisão, organizava currículo, planejamento, orientava professores, etc. Foi o local onde começou a MM [Matemática Moderna]. Eu diria que foi lá que foi implantado a MM. Nós começamos já com a MM. Nem tinha livros, a gente fazia o que chamávamos de bateria de atividades. Não adotávamos livros, justamente porque nós queríamos exercitar (BECHARA, 2007).

Já o Serviço de Ensino Vocacional (SEV) criou possibilidades de encontros e produção de representações sobre ensino moderno de Matemática. Consideramos a atuação do SEV como estratégia do governo para divulgar suas propostas de alterações metodológicas, fundamentadas na teoria psicogenética de Jean Piaget ${ }^{7}$, oferecendo cursos, palestras, estágios e visitas. O primeiro curso ocorreu em 1961, para preparar as primeiras unidades do Vocacional (GATTI; MELLO; BERNARDES, 1972). Esses cursos já começavam divulgando a Matemática Moderna, cuja ementa privilegiava assuntos referentes às novas metodologias de ensino e ideias divulgadas pelo Movimento. Eram gratuitos, optativos, funcionando fora do horário de trabalho. Os professores discutiam e criavam atividades que poderiam ser aplicadas e depois avaliadas (GATTI; MELLO; BERNARDES, 1972).

\footnotetext{
${ }^{6} \mathrm{Na}$ época (1960-1980), encontramos diferentes denominações para cursos direcionados a professores pelo poder público. Eram denominados de cursos de capacitação, treinamento de professores, de formação em serviço, entre outros.

7 Jean Piaget (1896-1980), em sua teoria, explica como o indivíduo, desde o nascimento, constrói o conhecimento. Especializou-se em Psicologia Evolutiva e em Epistemologia Genética. Seus estudos sobre Pedagogia, em grande medida, promoveram questionamentos sobre visões e teorias tradicionais relacionadas à aprendizagem (FRANÇA, 2012). Vários estudos abordam esse tema. Dentre eles, destacamos Piaget (2003).
} 
Muitas experiências metodológicas foram testadas no Vocacional e no Experimental da Lapa, que recebiam visitas de diversos professores:

Eu fazia cursos e ministrava cursos no Experimental da Lapa, Grupo Escolar Experimental Edmundo de Carvalho, quando a Anna [Franchi] veio trabalhar lá. Comecei a conhecê-la e admirar seu trabalho como professora primária. Já a Lucília [Bechara], era professora de Matemática no Vocacional. Aí encontramo-nos (LIBERMAN, 2006).

A ementa dos cursos variava de acordo com o interesse dos participantes, porém eram privilegiados os assuntos referentes a novas metodologias de ensino e às ideias divulgadas pela psicologia da aprendizagem. Eram gratuitos para todos os professores, funcionando como uma capacitação optativa, fora do horário de trabalho. Apesar de não serem voltados especificamente para o ensino primário, estudavam-se muito os textos de Piaget, o que motivava alguns professores ao aprofundamento da aprendizagem infantil de Matemática.

Após estudos baseados na bibliografia publicada pelo School Mathematics Study Group (SMSG) ${ }^{8}$, os professores discutiam e criavam atividades que poderiam ser aplicadas e depois avaliadas. "Durante o período de 1961 a 1969, o SEV realizou nove treinamentos com cinco meses de duração cada um. Os treinamentos tinham a finalidade de informar sobre o trabalho realizado por ele aperfeiçoar técnicas e metodologias aos docentes ingressantes" (GATTI; MELLO; BERNARDES, 1972, p. 10).

Ora, o SEV encarregava-se de todo o processo de formação pedagógica, desde o recrutamento até a avaliação dos cursos. Os candidatos a participarem dos ginásios vocacionais eram selecionados entre os professores da rede pública do Estado e, após entrevistas e provas escritas, passavam a integrar o quadro docente ou técnico do sistema.

Franchi, professora atuante durante o MMM, conheceu Liberman e Bechara nos espaços de estudo criados pelo Grupo de Estudos do Ensino em Matemática (GEEM), Vocacional do Brooklin e Experimental da Lapa. Nessa época, Franchi trabalhava como professora primária no Experimental da Lapa, e aplicava as atividades criadas nos grupos de estudo. Mais tarde, foi designada como Supervisora de Matemática do Grupo Experimental Dr. Edmundo de Carvalho.

Após as reuniões de estudos no Vocacional, as atividades eram elaboradas e testadas nas classes experimentais. Depois, avaliadas e registradas em unidades pedagógicas ${ }^{9}$ As

\footnotetext{
${ }^{8}$ Em 1958, iniciam-se os trabalhos do SMSG. O grupo foi fundado a partir de deliberações em Conferências promovidas pela National Science Foundation (NSF), em que a baixa qualidade do ensino elementar e secundário foi apontada como um dos fatores responsáveis pela escassez de matemáticos pesquisadores.

${ }^{9}$ Nas unidades pedagógicas realizavam-se levantamento, discussão de problemas e procurava-se sintetizar as conclusões. Na fase do estudo, utilizavam-se textos, livros, material das unidades e as estratégias adotadas (GATTI; MELLO; BERNARDES, 1972).
} 
reuniões passaram a constituir-se em um espaço de troca de experiências, sobre os modos de ensinar e divulgar as novas metodologias.

Aconteciam ainda os cursos no GEEM, que uniam uma elite de professores de Matemática comprometidos com as mudanças, empenhados em realizar um trabalho de reformulação curricular no qual acreditavam.

Acontecia também em São Paulo, os cursos para os Ginásios Vocacionais. No segundo semestre, estávamos estudando Matemática Moderna [MM] no curso do Mackenzie e também nos Ginásios Vocacionais. Ficamos entusiasmados, respirávamos MM. Nós estávamos estudando a questão do construtivismo, do cognitivismo, líamos muito Piaget [...]. Os seis estudos de Piaget (BECHARA, 2007).

Quando o professor Sangiorgi, presidente do GEEM, conseguiu financiamento para o "primeiro curso" realizado no Mackenzie, os professores que faziam o curso do Vocacional também optaram pelo curso do GEEM, encarando jornada dupla.

\footnotetext{
Muitas propostas metodológicas foram criadas nas reuniões do Vocacional. O professor Sangiorgi frequentava essas reuniões, preocupado com as respostas dos professores às novas proposições, já veiculadas em seus livros didáticos. O Sangiorgi aproveitava o conhecimento e a prática do Vocacional. Tinha um vínculo muito grande entre o Vocacional e o GEEM. Ele discutia, perguntava muito, conversava muito comigo. Queria saber como os alunos respondiam, do que os alunos gostavam (BECHARA, 2007).
}

As ideias defendidas pelo MMM foram divulgadas, por meio de documentos e cursos para professores, a toda rede de ensino paulista. Isso pode ser explicado, em grande medida, pela rede de sociabilidade trançada entre os professores defensores do Movimento, com o patrocínio da SEE de São Paulo, adotando-o como discurso oficial.

A SME seguiu os modelos do Estado. A cobrança da população por vagas em escolas municipais integradas, que funcionavam experimentalmente desde 1965, integrando o primário e ginásio, determinou ao governo municipal a urgência de um plano para a implantação da escola integrada de oito anos. Assim, em 1968, o Instituto Municipal de Educação e Pesquisas (IMEP) foi fundado. Competia ao órgão, administrado pela prefeitura e com orientação da Fundação Brasileira para o Desenvolvimento de Ensino de Ciências (FUNBEC), a elaboração de um plano administrativo e pedagógico para implantação da escola ampliada, em cumprimento à lei que estabelecia a obrigatoriedade escolar dos 7 aos 14 anos (SÃO PAULO, 1970).

A escola integrada de oito anos gerou muito interesse e divulgava suas experiências em várias publicações. Seu plano administrativo previa cursos de formação de professores 
com o objetivo de atualizar e integrar os professores nas novas propostas para a escola estendida de oito anos (GATTI; MELLO; BERNARDES, 1972).

O IMEP foi um lugar privilegiado para discussões e troca de experiências sobre o ensino de Matemática, visto que agregava educadores de diferentes instituições no mesmo espaço. Um exemplo da circulação das ideias reformistas pode ser observado pelo "trânsito profissional" de um desses docentes. Lydia Lamparelli, professora da rede pública de ensino, prestava serviço em várias instituições, como no projeto IBECC/UNESCO, na FUNBEC, no Centro de Treinamento para Professores de Ciências Exatas e Naturais de São Paulo (CECISP) e no IMEP, que, coincidentemente, funcionavam no mesmo prédio.

Este fato possibilitava várias parcerias, intercâmbios, sendo constantemente chamada a colaborar com os cursos de formação e elaboração de publicações referentes ao ensino e aprendizagem de Matemática, expedidas tanto pelo Município como pelo Estado.

\begin{abstract}
Para os cursos de formação, organizados pelo IMEP, vinham professores do Estado, do Experimental da Lapa, do Ginásio Vocacional Oswaldo Aranha, da escola Aplicação, outros eram professores efetivos do Estado com trabalhos relevantes na área. A professora Lydia era um contato e como no IMEP ela era coordenadora de Matemática, professora titular, docente de $5^{\mathrm{a}}$ a $8^{\mathrm{a}}$ série, organizava todo o trabalho de Matemática do projeto, trazendo muitos professores de Matemática do GEEM, como a professora Lucília, facilitando a troca de experiências (MANSUTTI, 2011).
\end{abstract}

A dinâmica da política educacional municipal para a implantação das reformulações atribuía protocolos de funcionamento semelhantes aos do Estado, talvez consequência da rede de relações construídas por seus professores que compactuavam com o ideário do MMM e gozavam de prestígio entre os docentes, em cargos de comando em seus quadros, possibilitando maior divulgação de suas ideias. Identificamos a equipe de professores, a maioria deles, oriundos da escola de aplicação do Estado Vocacional, como relevante no processo de produção de experiências metodológicas e, consequentemente, de interesse pelos cursos ministrados.

\title{
Considerações finais
}

Acreditamos que o estudo que explore o diálogo entre passado e presente, que procura compreender as condições que permitiram a produção das representações sobre como ensinar e aprender Matemática, postas a circular em publicações oficiais, pode subsidiar as problematizações diárias sobre a prática e possíveis novas propostas, na medida em que auxilia na atribuição de significados a situações de aprendizagem, às quais somos expostos a todo momento e a que respondemos muitas vezes com ações engessadas. Nessa perspectiva, o 
exame de documentos oficiais poderá alargar a compreensão dos diferentes processos de apropriação de um mesmo ideário. Isso implicou seguir e procurar desvendar os processos de apropriação utilizados pelos elaboradores desses documentos, além de caracterizar e diferenciar o MMM no Ensino Primário.

Este artigo procurou discutir como as ideias defendidas pelo Movimento da Matemática Moderna (MMM) nas décadas de 1960 e 1970, no estado de São Paulo, Brasil, foram implementadas. Para isso consideramos as Leis 4.024/61 e 5672/71, o impresso direcionado para professores publicado pelos órgãos oficiais de Educação, contendo sugestões sobre os modos de fazer em sala de aula, entrevista com professores autores de livros didáticos da época, elaboradores de publicações e participantes do Movimento como contextos de sustentação.

A necessidade de democratização do ensino pode auxiliar a compreender por que as mudanças no ensino, defendidas pelo MMM foram eleitas como as mais adequadas a um novo contexto sociopolítico-econômico, na medida em que o MMM prometia uma Matemática mais ajustada aos novos tempos, acesso aos novos avanços da disciplina, oferecendo instrumentos para o acesso a uma nova sociedade tecnológica e mais científica. Assim, protagonistas do MMM obtiveram privilégios e financiamentos, podendo mais facilmente fazer circular suas propostas de alterações para o ensino, particularmente nas séries iniciais, e seu ideário ser prontamente apoiado pelo governo por meio de financiamentos.

Os documentos expedidos pelas Secretarias paulistas podem assinalar uma dupla função: são utilizados como estratégia para implementar a reformulação curricular e divulgação das novas diretivas para o ensino de Matemática e para fazer circular a representação de que a nova maneira de ensinar Matemática seria a mais adequada.

\section{Referências}

ALMEIDA, M. W. B. Simetria e entropia: sobre a noção de estrutura de Lévi-Strauss.

Revista de Antropologia, São Paulo, v. 42, n. 1-2, p. 163-197, 1999.

BECHARA, L. Depoimento oral. Entrevistas concedidas a Denise Medina, 2007.

BRASIL. Lei 4.024, de 20 de dezembro de 1961. Lei de Diretrizes e Bases da Educação Nacional. 1961. Brasília: Ministério da Educação e Cultura. Recuperado em 27 maio, 2017. Disponível em: http://www.jusbrasil.com.br/legislacao/129047/lei-de-diretrizes-e-base-de1961-lei-4024-61.

BRASIL. Lei n. 5.537, de 21 de novembro de 1968. Cria o Instituto Nacional de Desenvolvimento da Educação e Pesquisa (INDEP), e dá outras providências. Brasília: 
Ministério da Educação e Cultura. Recuperado em 19 maio, 2017. Disponível em: http://www.jusbrasil.com.br/legislacao/104125/lei-5537-68.

BRASIL. Lei 5.692, de 11 de agosto de 1971. Lei de Diretrizes e Bases da Educação Nacional. Brasília: Ministério da Educação e Cultura. Recuperado em 26 maio, 2017. Disponível em: http://www.planalto.gov.br/ccivil_03/leis/15692.htm.

CHARTIER, R. O mundo como representação. Estudos Avançados, 5 (11), 1991. Recuperado em 29 maio, 2017. Disponível em: http://www.scielo.br/pdf/ea/v5n11/v5n11a10.pdf.

DE CERTEAU, M. A invenção do cotidiano. Artes de fazer. Petrópolis, RJ: Vozes, 2002.

FRANÇA, D. M. de A. Do primário ao primeiro grau: as transformações da matemática nas orientações das Secretarias de Educação de São Paulo (1961 - 1979). 2012. Tese (Doutorado em Educação) - Faculdade de Educação, Universidade de São Paulo, São Paulo, 2012. Disponível em: < http://www.teses.usp.br/teses/disponiveis/48/48134/tde-14052013103937/pt-br.php>. Acesso em: 20 out. 2017.

GATTI, B. A.; MELLO, G. N. de; BERNARDES, N. M. G. Algumas considerações sobre treinamento de pessoal no ensino. Cadernos de Pesquisa. Fundação Carlos Chagas, Departamento de Pesquisas Educacionais, 1972.

HILSDORF, M. L. História da educação brasileira: Leituras. São Paulo: Pioneira Thomson Learning, 2005.

LIBERMAN, M. Depoimento oral. São Paulo, 18 dez. 2006. Entrevista concedida a Denise Medina.

MANSUTTI, M. A. Depoimento oral. São Paulo, 18 mai. 2011. Entrevista concedida a Denise Medina.

PIAGET, J. Seis estudos de psicologia. 24. ed. Rio de Janeiro: Forense Universitária, 2003.

RIBEIRO, M. L. História da educação brasileira: a organização escolar. Campinas, SP: Autores Associados, 1986.

ROMANELLI, O. História da educação no Brasil. 3. ed. Petrópolis: RJ: Vozes, 1982.

SÃO PAULO. Secretaria de Educação e Cultura do Município de São Paulo. Departamento Municipal de Ensino (DME). Instituto Municipal de Educação e Pesquisa (IMEP). Relatório do trabalho realizado no 1o Trimestre de 1970. São Paulo: SME,1970.

SÃO PAULO. Plano Estadual de Educação. Programa da Escola Primária do Estado de São Paulo. São Paulo: SEE, 1969. 
SÃO PAULO. Decreto n. 38.643, de 27 de junho de 1961. Dispõe sôbre o ensino industrial, ensino de economia doméstica e de artes aplicadas e cursos vocacionais. São Paulo: SEE, 1961. Recuperado em 29 maio, 2017. Disponível em:

http://www.al.sp.gov.br/repositorio/legislacao/decreto/1961/decreto-38643-27.06.1961.html.

TAMBERLINI, A. R. M. B. Os ginásios vocacionais: a dimensão política de um projeto pedagógico transformador. São Paulo: Annablume, 2001.

VITTI, C. Movimento da matemática moderna: memória, vaias e aplausos. 1998. Tese (Doutorado em Educação) - Universidade Metodista de Piracicaba, Piracicaba, 1998. 